\title{
ENFERMAGEM
}

\section{ACIDENTE DE TRÂNSITO E ENFERMAGEM: UMA PARCERIA NECESSÁRIA NO CONTEXTO DA PROMOÇÃO DE SAÚDE}

\author{
DOI: http://dx.doi.org/10.31072/rcf.v8i2.503
TRAFFIC ACCIDENT AND NURSING: A NECESSARY PARTNERSHIP IN THE CONTEXT OF HEALTH PROMOTION

Rafaela Cristina Bandeira Maia1; Rogério Anderson Souza dos Santos²; Rosani Aparecida Alves Ribeiro de Souza ${ }^{3}$; Rafael Alves Pereira ${ }^{4}$.

RESUMO: O trânsito é de fundamental importância e está em constante utilização no cotidiano da humanidade, porém o Acidente de Trânsito (AT) tem se tornado um fato rotineiro, angariando sérios reflexos aos serviços de saúde. Atualmente, já é considerado pela Organização Mundial da Saúde (OMS) como um problema de saúde pública, tanto no Brasil quanto em nível mundial, condição esta que exige políticas de intervenção preventiva. $O$ objetivo é discorrer sobre o papel da enfermagem no processo de sensibilização visando à prevenção de AT, diante de sua posição privilegiada junto à população. Trata-se de uma revisão bibliográfica, motivada pelos elevados números de acidentes no trânsito evidenciados nos últimos anos. As principais causas de AT, ao contrário do muitos pensam, não estão apenas relacionadas com as más condições das vias e a falta de sinalização e sim, em sua maior parte, estão associadas às condutas adotadas pelos integrantes do trânsito, a exemplo da embriaguez na direção, o excesso de velocidade e o uso de aparelho celular na direção. Nessa perspectiva, o profissional enfermeiro destaca-se, sobretudo, como promotor de saúde, dada a sua formação humanística, com foco em educação em saúde e para a saúde, além de possuir uma atuação mais próxima da população, favorecendo dessa forma, a elaboração de estratégias mais eficazes e efetivas, como também aplicação destas. Diante do exposto, intenciona-se com este estudo uma singela contribuição, com vistas à elaboração e ao fortalecimento de políticas promocionais, dando maior autonomia aos sujeitos usuários dos serviços e bens de saúde pública.

\footnotetext{
1 Bacharel em Enfermagem pela Faculdade de Educação e Meio Ambiente - FAEMA. Pós Graduação em andamento em Gestão e Logística Hospitalar pela Universidade Cândido Mendes. E-mail: rafaela_maia.2012@hotmail.com. ORCID: https://orcid.org/0000-0003-1189-5391;

2 Bacharel em Enfermagem pela Faculdade de Educação e Meio Ambiente - FAEMA. E-mail: rogerio.wnet@gmail.com. ORCID: https://orcid.org/0000-0002-5372-9458;

3 Doutorado em Odontologia Preventiva e Social (Conceito CAPES 4) - UNESP. Mestrado em Odontologia Preventiva e Social (Conceito CAPES 4) - UNESP, Brasil. Especialização em Saúde Coletiva pela Universidade Estadual Paulista Júlio de Mesquita Filho - UNESP. Especialização em Dentística Restauradora - USP. Especialização em Endodontia - USP. Aperfeiçoamento em Odontopediatria pela Associação Odontológica do Norte do Paraná - AONP. E-mail: rosani.alves@faema.edu.br. ORCID: https://orcid.org/0000-0002-5996-0837;

4 Bacharel em Enfermagem pela Faculdade de Educação e Meio Ambiente - FAEMA. Especialização em andamento em Fisiologia Humana Aplicada as Ciências da Saúde - UNESA. Especialização em Saúde Pública - UNOPAR. E-mail: rafaelalves648@gmail.com. ORCID: https://orcid.org/0000-0001-9067-3767.
} 
Descritores (DeCS): Saúde pública. Processo saúde-doença. Papel do profissional de enfermagem.

ABSTRACT: Traffic is a significant matter and is in constant occurence in the day to day events of humanity, but the Traffic Accident (AT) has become a routine fact, bringing serious reflexes to health services. Currently, it is already considered by the World Health Organization (WHO) as a public health problem, both in Brazil and worldwide, a condition that requires prophylacticintervention policies. The objective is to discuss the role of nursing in the process of awereness aimed at the prevention of TA, given its privileged position within the general population. This is a bibliographical review, motivated by the elevated number of traffic acidentes occurred in recent years. The main causes of TA, contrary to what many people believe, are not only related to poor road conditions and lack of signaling, but, for the most part, are associated with the behaviors adopted by people commuting, such as D.U.I. (driving under influence), speeding and the use of mobile devices while driving. From this perspective, the nurse professional stands out, above all, as a health promoter, given his humanistic education, with a focus on health and health education, also having a closer relationship to the population, thus favoring the elaboration of more effective strategies, as well as their application. In view of the above, this study intends a simple contribution, with a view to the elaboration and strengthening of promotional policies, giving greater autonomy to the users of public health services and assets.

Descriptors: Public health. Health-disease process. Role of the nursing professional.

\section{INTRODUÇÃO}

Vivencia-se um momento histórico em pleno século $\mathrm{XXI}$, referente aos Acidentes de Trânsito (AT) em todo o mundo, fazendo com que chame, não somente a atenção, mas também a atuação das principais instituições mundiais, a citar a Organização das Nações Unidas (ONU), Banco Mundial e Organização Mundial de Saúde (OMS). Dentre tais atuações, menciona-se o alerta e incentivo aos países em intervir e combater os altos índices de acidentes de trânsito. (1)

Atualmente, os Acidentes de Trânsito (AT) têm constituído importante problemática de saúde pública em nível mundial, principalmente, se relacionarmos aos elevados índices de vítimas e de mortalidade. Estima-se que cerca de 1,2 milhões de pessoas morrem por ano no mundo e 50 milhões sofrem sérias lesões. Algumas pesquisas já consideram esses dados como epidemia e apontam como principal agente causador de tal fato, a falta de sensibilização ao que se refere à conscientização no trânsito. (2)

O Brasil tem mostrado preocupante crescimento em índices de morbidade e mortalidade por AT nas três últimas décadas. Dados registrados entre os anos de 1980 e 2011 contabilizaram quase um milhão de mortos, mais precisamente, 
980.838 mortes no trânsito brasileiro. Obtendo um destaque ainda maior na última década, entre os anos 2000 e 2011, tanto pelo número de mortos por AT, que passou de 28.995 no ano de 2000 para 43.256 no ano de 2011, correspondendo a um aumento expressivo de 49,2\%, quanto pelo fato de que nesta década o trânsito já havia passado a ser regulamentado pelo novo Código de Trânsito Brasileiro (CTB), onde mesmo sob o regimento deste código, esse período de tempo demonstrou um constante e significativo aumento. ${ }^{(3)}$

Pautando-se em tal perspectiva, pode-se perceber que o trânsito, encontrase em uma constante guerra não declarada, presente em todo o mundo, onde todos são alvos em potencial e simultaneamente partes corresponsáveis. (4)

Considerando o elevado número de AT, este estudo se justifica à medida que propõe discorrer sobre 0 papel da enfermagem no processo de sensibilização visando à prevenção de $\mathrm{AT}$, de forma a reduzir os índices de morbimortalidade, sob a lógica do processo saúde-doença, dos impactos socioeconômicos, bem como seus reflexos no Sistema Único de Saúde (SUS).

Assim, considera-se o enfermeiro como sendo um elemento de extrema importância nas ações preventivas, as quais podem ser estabelecidas a partir do diálogo e da interação com a população, uma vez ocupa posição privilegiada nos serviços de saúde.

\section{METODOLOGIA}

Trata-se de um estudo de revisão bibliográfica, realizado por meio de análise criteriosa de publicações acadêmicocientíficas, as quais abordavam a temática de AT e seus reflexos na saúde pública.

A revisão bibliográfica constitui um método de estudo caracterizado pela busca, análise meticulosa e descrição de um conjunto de conhecimentos envolvendo determinada temática. Este método vale-se de publicações relevantes, como as disponibilizadas em livros, artigos, periódicos, relatórios governamentais, teses, dissertações e outros, para construção de uma linha de raciocínio. São de maneira geral importantes, pois podem além de reproduzir uma ideia, contribui significativamente na reformulação de pensamentos acadêmicos, permitindo a formulação de novas direções de saberes, impulsionando novas descobertas e estimulando o pensamento crítico.

Para busca efetiva dos materiais a serem analisados, foram utilizadas como bases de dados, a Biblioteca Virtual da Saúde (BVS), Scielo (Scientific Eletronic Library Online), Manuais de Normas Técnicas do Ministério da Saúde e 
Ministério das Cidades, livros e outros conteúdos científicos da Biblioteca Júlio Bordignon, além de obras de acervos próprios dos autores.

Os Descritores em Saúde (DeCS) utilizados para as buscas foram os seguintes: Acidentes de Trânsito, Saúde Pública e Papel do Profissional de Enfermagem.

Não houve emprego de um delineamento temporal específico, visto que, algumas bibliografias consideradas antigas foram utilizadas neste estudo, devido à grande relevância destas para esta pesquisa. Como exemplo, pode-se citar a "Lei no 9503, de 23 de setembro de 1997".

Os critérios de inclusão foram: materiais disponíveis em bases de dados confiáveis de maneira integral, em língua portuguesa, inglesa ou espanhola e que tivessem conexão com a temática proposta. Não foram utilizados materiais que não estivessem de acordo com os critérios de inclusão acima descritos.
Foram encontrados um total de 79 bibliografias, destes, foram utilizadas 39 $(100 \%)$, das quais, $20(51,28 \%)$ unidades constituíam artigos, 01 (2,56\%) Lei, 01 (2,56\%) Resolução, 02 (5,13\%) livros, 05 $(12,82 \%)$ foram trabalhos de conclusão de curso, teses, dissertações ou monografias, $09(23,08 \%)$ foram materiais indexados a revistas eletrônicas e 01 (2,56\%) foi material disponibilizado pelo Conselho Federal que representavam a classe de enfermagem.

\section{REVISÃO DE LITERATURA}

\subsection{Acidentes de trânsito: produto da relação do homem versus trânsito}

O trânsito, segundo o CTB, é definido como:

[...] utilização das vias por pessoas, veículos e animais, isolados ou em grupos, conduzidos ou não, para fins de circulação, parada, estacionamento e operação de carga ou descarga ${ }^{(5)}$.

A partir desta definição, cria-se a necessidade de se conhecer os quatro (04) principais elementos do trânsito, especificados no Quadro 1.

Quadro 1 - Descrição dos principais elementos que compõem o trânsito.

\begin{tabular}{|c|l|}
\hline ELEMENTOS & \multicolumn{1}{c|}{ DESCRIÇÃO DOS ELEMENTOS } \\
\hline O Ser Humano & $\begin{array}{l}\text { Todo aquele que utiliza as Vias Públicas(VP) para ir e vir transportando ou } \\
\text { não coisas, a pé (pedestre), a cavalo, conduzindo veículo, ou mesmo sendo } \\
\text { passageiro. }\end{array}$ \\
\hline A Via & $\begin{array}{l}\text { O local onde circulam pessoas, veículos e animais, abrangido pela pista, } \\
\text { canteiro central, acostamento, e calçada que, por sua vez, é de uso exclusivo } \\
\text { dos pedestres. }\end{array}$ \\
\hline O Veículo & $\begin{array}{l}\text { Todo meio de transporte utilizado para a locomoção ou transporte de } \\
\text { pessoas ou carga, como por exemplo: motocicletas e automóveis } \\
\text { (automotores), bicicleta e carrinho de mão (propulsão humana), carroça } \\
\text { (tração animal). }\end{array}$ \\
\hline
\end{tabular}




\begin{tabular}{|c|l|}
\hline Os Animais & $\begin{array}{l}\text { Todos os tipos de animais que se encontram nas vias, tanto animais de } \\
\text { montaria (cavalos e bois), quanto animais silvestres, que cruzam as vias e } \\
\text { animais domésticos soltos nas ruas, que é algo errado devido os riscos que } \\
\text { eles expõem aos usuários do trânsito. }\end{array}$ \\
\hline
\end{tabular}

Fonte: Adaptado de BRASIL (2015).

O trânsito passou a existir desde 0 surgimento do próprio ser humano, diante de necessidades constantes de movimentação, locomoção ou deslocamentos, de modo a se desenvolver juntamente com 0 progresso das civilizações, agregando vários tipos de animais e veículos em seu processo, ademais, a criação de instrumentos que auxiliassem nesse método, tais como, a criação da roda. (6)

De acordo com os mesmos autores, dentre tantas civilizações que existiram, no decorrer dos tempos, o Império Romano se destacou com uma imensa rede de estradas de acesso aos tantos territórios que estavam em seu domínio, tendo Roma como centro, a qual possuía o acesso principal de todas as vias construídas pelo seu império. No entanto, após observar alguns problemas, a exemplo da danificação de vias, o imperador Julio Cesar criou normas específicas para o trânsito de Roma, (acredita-se ser o primeiro a implantar algum tipo de regulamento no trânsito), valendo citar a proibição de movimentação de qualquer tipo de meio de transporte de rodas no centro de Roma.
A exposição de tal contexto, portanto, faz-nos perceber que o trânsito, não vem a ser um objeto novo diante da humanidade, nem tão pouco de baixo valor, a considerar que o mesmo está presente desde a antiguidade, bem como a necessidade de sua organização.

Diante desta íntima relação de desenvolvimento entre 0 trânsito e o homem, foram criados caminhos, estradas e/ou vias, juntamente com o uso de animais e veículos. Em meio a este cenário, houve a chamada Revolução Industrial, que em1891, proporcionou um momento histórico, passando a circular no Brasil, mais precisamente no estado de São Paulo, o primeiro veículo com motor (Peugeot com motor alemão) adquirido em Paris por Henrique Santos Dumont. A partir daí, o ano 1904 se destacou pelo início efetivo da importação de veículos para o Brasil. (7)

Assim, como na história geral, que houve necessidade de normatizar e criar regras no decorrer do desenvolvimento do trânsito, o Brasil passou a criar regulamentos. Por conseguinte, no final do século $X X$, a Lei $n^{-}$9503, de 23 de setembro de 1997, passou a regulamentar 
o trânsito em todo o território brasileiro, instituindo, o ainda vigente, CTB. ${ }^{(8)}$

\subsubsection{Acidentes de trânsito e sua anatomia}

Historicamente, o AT se perpetuou como consequência da relação homem $x$ trânsito. O primeiro AT no Brasil foi com um veículo francês, adquirido no ano de 1897 , por José do Patrocínio que, em certa ocasião, emprestou para o poeta Olavo Bilac, que sem ter muita prática, veio a se chocar com uma árvore. ${ }^{(6)}$

Contudo, os ATs receberam um grande impulso durante o século $X X$, devido à colossal Revolução Industrial que se tornou um marco histórico para trânsito, sendo responsável pelo crescente e significativo aumento de veículos, que em conjunto com as más condutas dos usuários e uma defasada fiscalização e estrutura física, que, por sua vez, nem sempre conseguiu acompanhar esse crescimento, fez com que o AT se tornasse o protagonista desse enredo, sendo o Brasil um dos principais palcos deste fato lastimável. (9)

No ano de 2010, segundo a OMS, em 182 países foram registrados quase 50 milhões de pessoas com algum tipo de ferimento grave ou sequela, decorrente de AT, no mesmo ano, verificou-se um quantitativo de 1,24 milhões de mortes oriundas da mesma problemática. Deste modo, o AT, passou a ser considerado em 2013, a terceira causa de morte em pessoas com idade entre 30 a 44 anos. ${ }^{(3)}$

Figura 1 - Número de mortes (mil) em acidentes de trânsito. Brasil, 1980 à 2011.

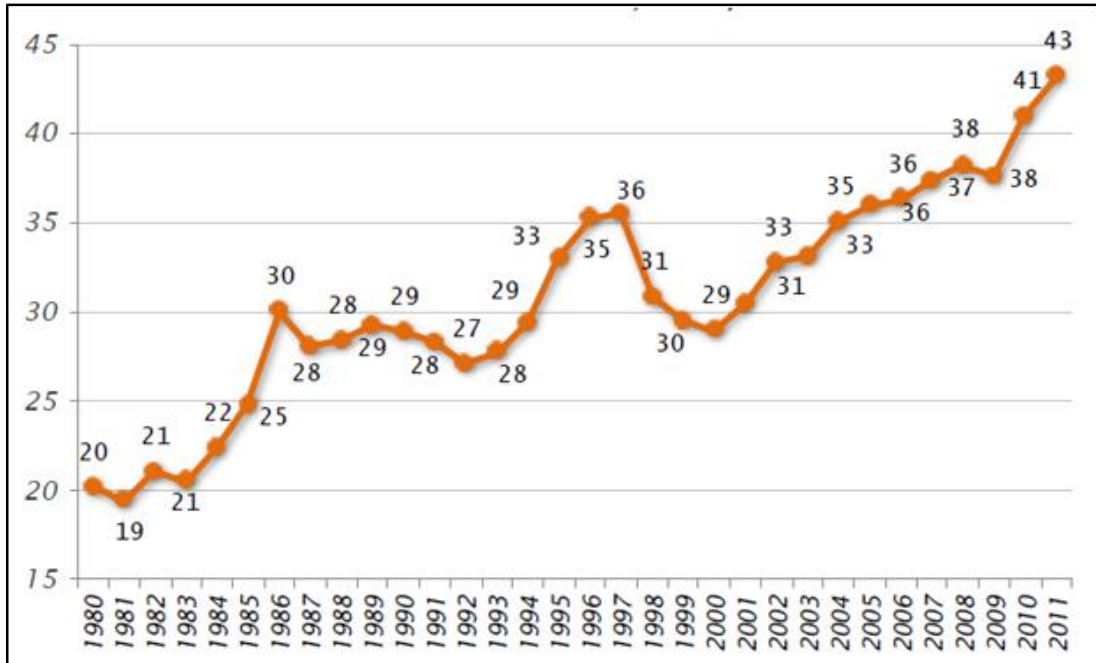

Fonte: (WAISELFISZ, 2013).

De acordo com o autor acima, os dados registrados entre os anos de $1980 \mathrm{e}$ 2011 contabilizaram, no Brasil, quase um milhão de mortos em AT, mais precisamente, 980.838 mortes no trânsito. Nessa perspectiva, ao considerar apenas 0 
período entre os anos de 2000 e 2011 , o número de AT passou de 28.995 no ano de 2000 para 43.256 no ano de 2011 , correspondendo a um aumento expressivo de $49,2 \%$, sendo que neste período, o trânsito no Brasil, já se encontrava regulamentado pelo atual CTB, em que neste período, mesmo sob o regimento deste código, demonstrou um constante e significativo aumento.

A Figura 1, ilustra um gráfico que detalhada o número mortes decorrentes de AT por ano no Brasil:

Alves (10) utilizando como base a Associação Brasileira de Normas Técnicas (ABNT), menciona em seu estudo a definição de AT como sendo "todo evento não premeditado que resulte dano em veículo ou na sua carga e/ou lesões em pessoas e/ou animais, em que pelo menos uma das partes está em movimento nas vias terrestres ou áreas abertas ao público. Pode originar-se, terminar ou envolver veículo parcialmente na via pública. "

No entanto, para a contextualização coesiva deste estudo, ressalta-se segundo Waiselfisz ${ }^{(3)}$, que apesar de sua definição afirmar que seja algo não pensado, é ainda, na maioria das vezes entendido pela sociedade em geral, como sendo uma situação casual, não planejada e inevitável. Existem sim, no AT, situações evitáveis em que o usuário do trânsito tem plena consciência das consequências de suas ações, destacando uma ausência de sensibilização quanto ao uso consciente do trânsito, a fim de promover um trânsito seguro.

No mesmo sentido, é importante considerar que o CTB por meio de seus princípios, regras e normatizações, objetiva garantir a todos o direito de um trânsito seguro e impõe ao Sistema Nacional de Trânsito (SNT), o dever de priorizar a defesa da vida, no qual também englobam a preservação da saúde e do meio ambiente. ${ }^{(7)}$

Para uma análise do AT, em publicação do Ministério da Saúde (MS), postula-se a anatomia do AT, o qual consiste na estrutura básica do acidente, ou seja, identificação dos agentes envolvidos, podendo citar a pessoa, a via, o veículo, o ambiente e $\mathrm{O}$ aparato institucional. Em suma, constitui basicamente a análise isolada e criteriosa de todos os agentes envolvidos. (11)

Deste modo, o estudo da anatomia de um AT, permite ao identificar os elementos envolvidos, averiguar e direcionar os custos envolvidos em cada elemento identificado no acidente. Vale mencionar, que além dos agentes comuns a um AT, como os citados acima, no quadro 01 , existem outros elementos que devem ser averiguados, principalmente, ao abordar a questão de 
gastos envolvidos. Vale mencionar entre eles, os atendimentos pré-hospitalares; hospitalares; pós-hospitalares; além de itens como a "perda de produção; remoção/translado; gasto previdenciário; danos materiais; perda de carga; remoção/pátio; reposição; processos judiciais; atendimento policial; danos à propriedade pública e privada." (12)

O Instituto de Pesquisa Econômica Aplicada (IPEA) acrescenta e intitula que: "O estudo da "morfologia de um acidente" é campo de pesquisa que vai além da descrição das formas dos acidentes, buscando explicar as conexões existentes entre os diversos elementos, considerando a dinâmica do acidente, visualizando-o em uma dimensão temporal, estudando as forças atuantes durante o período em que 0 acidente ocorreu, os materiais, sua resistência e deformação, incluindo-se o que se poderia chamar de "fisiologia dos materiais". (13)

Considerando o exposto, é importante destacar que uma análise delineada de um AT pode, por sua vez, facilitar o planejamento e o trabalho de órgãos envolvidos principalmente em estratégias de prevenção, visto que esta permite, também, identificar locais, meses, dias e horários que evidenciam menor e maior pico de AT, permitindo deste modo, direcionar as atividades a serem desenvolvidas. ${ }^{(11)}$

3.1.2 Principais causas dos acidentes de trânsito

Para dar início à abordagem das principais causas dos ATs, é importante destacar que, ao contrário do que muitos pensam, segundo Almeida (14), o principal agente influenciador para a ocorrência dos ATs, é o próprio ser humano com suas atitudes irresponsáveis e não as vias ou os veículos, como muitos costumam falar. $\mathrm{E}$ ainda acrescenta, mencionando que "todos esses fatores contribuem para o aumento dos riscos, mas a maior razão para o massacre no trânsito é que nós, brasileiros, dirigimos muito mal". Coloca ainda, que, 95\% das causas dos ATs, estão diretamente ligadas às próprias condutas humanas, sendo os demais $5 \%$, correspondentes à soma total dos demais fatores.

A partir de então, o presente estudo, destaca três principais causas que contribuem significativamente com os elevados índices de AT, as quais estão relacionadas às irresponsabilidades dos motoristas, citando a embriaguez na direção (dirigir alcoolizado), excesso de velocidade no trânsito, ademais, a utilização do celular na direção. ${ }^{(15,16)}$

As duas primeiras causas acima apresentadas se destacaram entre as 
principais causas de AT em todos os países, de acordo com a World Health Organization (WHO) ${ }^{(16)}$, no Relatório Global de Segurança no Trânsito 2013, desenvolvido com finalidade de apoio à Década de Ação para a Segurança Rodoviária 2011-2020 declarada pela Assembleia Geral das Nações Unidas em 2010 que, por sua vez, objetiva reduzir expressivamente, os altos índices de acidentes e mortes no trânsito de 182 países, incluindo o Brasil.

Com relação ao uso do celular enquanto se dirige, estudos realizados alguns países dentre eles o Brasil e os Estados Unidos da América (EUA), observaram que nos últimos anos, houve uma elevação abrupta do uso $e$ envolvimento dos celulares no trânsito, tanto que, os índices de AT que envolvem tal temática como causa, se equipararam aos causados por embriaguez na direção. (15)

O CTB possui Leis de Trânsito (regras de circulação) que proíbem as infrações citadas acima, desde 1997, passando por algumas alterações no decorrer do tempo (no valor das multas, por exemplo). Estas Leis são aplicadas, através do Auto de Infração de Trânsito (AIT) pelos Agentes da Autoridade de Trânsito (pessoa civil ou militar credenciada pela a Autoridade de Trânsito). Acarretando na geração da multa pela Autoridade de Trânsito (dirigente máximo de órgão ou entidade executivo integrante do SNT ou pessoa por ele expressamente credenciada), como, por exemplo, o Departamento Estadual de Trânsito (17)

Conforme Borges ${ }^{(18)}$, o álcool (etanol, encontrado nas bebidas -cerveja, vinho, cachaça, entre outros) possui ação depressora no sistema nervoso central do usuário, além de causar outras alterações que afetam atividades motoras e atividades que exijam raciocínio e concentração, independentemente da quantidade de álcool no organismo. $O$ autor acresce também, que $\mathrm{O}$ álcool aumenta a desinibição e a autoconfiança, estimulando o indivíduo a realizar ou tentar realizar ações e/ou tomar decisões, acreditando que pode e consegue dirigir da mesma forma de quando não ingeriu bebida alcoólica.

Assim, segundo a Secretaria Nacional de Políticas sobre Drogas, ao relacionar álcool e trânsito, os usuários do trânsito se expõem às diversas variáveis com possíveis resultados catastróficos. Considerando que, as ações para conduzir um veículo exigem, sobretudo, coordenação motora e reflexos, a combinação desta atividade com a ingestão de álcool, pode ser considerada perigosa, a saber, o tempo de ação e percepção 
motorista ficam prejudicadas, devido à ação do álcool no organismo, o que compromete toda a segurança do trânsito. ${ }^{(19)}$

Deste modo, o álcool vem sendo eleito, o principal fator contribuinte para os ATs, sendo já é considerado o principal vilão deste cenário. Ao relacionar as mortes decorrentes dos ATs no Brasil, o álcool está diretamente relacionado, em aproximadamente, $70 \%$ dos casos de acidentes fatais. (20)

De acordo com a legislação vigente no Brasil, o ato de dirigir sob o efeito de álcool, pode ser considerado, tanto como uma infração gravíssima, a qual está prevista no artigo 165 do CTB, como também, um crime, de acordo com o previsto no artigo 306, deste mesmo código. (5) Para a verificação da embriaguez e diferenciação da infração ou do crime, comumente, faz-se uso de um aparelho denominado elilômetro (conhecido como bafômetro), capaz medir a quantidade de álcool (em miligramas) por litro de ar expirado pelos pulmões. ${ }^{(17)}$

É importante salientar que, atualmente, o Brasil possui uma tolerância zero álcool, conhecida como Lei Seca, ou seja, o condutor do veículo, não pode apresentar percentual algum de álcool no organismo, tanto que, ao constar no teste realizado pelo etilômetro um valor de álcool de $0,05 \mathrm{mg} / \mathrm{L}$ à $0,33 \mathrm{mg} / \mathrm{L}$, já respeitando $\mathrm{a}$ margem de erro de $0,032 \mathrm{mg} / \mathrm{L}$, o motorista receberá penalidades administrativas, como multa e perda do seu direito de dirigir por um ano, além do fato de ter o seu veículo retido. Já no caso deste valor for igual ou superior a $0,34 \mathrm{mg} / \mathrm{L}$, além das penalidades administrativas, responderá criminalmente podendo ser condenado de 03 meses a 03 anos de detenção. ${ }^{(15,16,5)}$

Além disso, o consumo de álcool em sua maior parte, segundo Borges ${ }^{(18)}$, tem início aos 16 anos, sendo o ápice do consumo, dos 18 aos 24 anos. Tal fato pode estar relacionado à forte influência da mídia, bem como, à comercialização livre desses itens, o que favorece o acesso para menores de idade (menos que 18 anos), embora haja legislações proibitivas quanto ao acesso a tais itens por essa clientela, porém, são muitas as dificuldades para que ocorra efetiva cobrança/fiscalização.

Estudos referentes aos principais problemas e causas de ATs têm demonstrado que, além do álcool, o excesso de velocidade, tem sido mais um dos grandes influenciadores dos autos índices de AT, deixando um longo histórico de mortes e mutilados. (21)

Além de influenciar no aumento efetivo dos acidentes, o excesso de velocidade se torna um fator crítico para o ser humano e pode tornar-se um agravante dos resultados provocados pelo acidente. Nesta perspectiva, cita-se que um corpo em 
fase adulta, tendo com base referencial o seu peso em quilogramas $(\mathrm{kg})$ possui uma resistência três (03) vezes superior ao seu peso em termos gerais. Assim, em uma colisão, estando o veículo em uma velocidade média de 60 quilômetros por hora $(\mathrm{Km} / \mathrm{h})$, o peso corporal dos ocupantes desse veículo, atingirá um valor de, aproximadamente, cinquenta vezes o valor normal. Por exemplo, se o ocupante for um adulto de $70 \mathrm{~kg}$, ele atingirá e sofrerá um impacto de $3500 \mathrm{~kg}$, do mesmo modo, se for uma criança de $20 \mathrm{~kg}$, atingirá um impacto com valor de $1000 \mathrm{~kg}$, fincando sujeito à fraturas gravíssimas e perda de sua vida. (22)

Considerando as questões expostas, todas as vias possuem limites de velocidade máxima permitida, visando à segurança do trânsito, sendo que tais limites são calculados de acordo com as funções e condições específicas de cada via. Normalmente, são utilizados sistemas de placas, com indicação destes limites em $\mathrm{k} / \mathrm{m}$, para alertar e informar o condutor. ${ }^{(5)}$

Vale ressaltar que no artigo 218 do CTB, o transitar em velocidade superior à especificada pelas placas em suas respectivas vias, é considerado infração. É considerada infração média, transitar em velocidade de até $20 \%$ acima do limite permitido, infração grave transitar em velocidade superior a $20 \%$ até $50 \%$ acima do permitido e infração gravíssima, para quem exceder em50\% a velocidade máxima da via. ${ }^{(15,05)}$

A utilização do aparelho celular está cada vez mais presente na vida do homem moderno, sendo utilizado de modo generalizado e até inconsequente, quando se relaciona ao ato de dirigir. Estudos realizados na Universidade de Utah dos EUA, demonstraram resultados alarmantes, evidenciando que as probabilidades de envolvimento em um AT pelo uso do celular, chegaram a aumentar $400 \%$. ${ }^{(15)}$

E no Brasil, alguns estudos sinalizam que é tão perigoso dirigir utilizando o celular de alguma forma, quanto dirigir sob a influência de álcool. O CTB, no inciso VI do artigo 252, prevê tal ação, como infração gravíssima, com aplicação de multa. ${ }^{(05,15)}$

Ainda neste contexto, segundo o DETRAN, no ano de 2014 foi constatado que no Estado de Rondônia a infração de trânsito que obteve 0 maior destaque foi justamente o uso do celular na direção, superando todas as outras, incluindo o excesso de velocidade e embriaguez na direção, ao ponto de ocupar o primeiro lugar no ranking das infrações com mais autuações (advertência administrativas/multas) no respectivo ano. (23) 


\subsection{Reflexos dos acidentes de trânsito} na saúde pública e na vida em sociedade

De acordo com a OMS ${ }^{(4)}$, os ATs constituem importante problema de saúde pública, visto que este já é tido como uma das principais causas de morte entre as pessoas, sendo causador de um elevado número de mortos, feridos, sequelados e pessoas incapacitadas no mundo.

Nesta mesma dimensão e considerando ideologias do IPEA (1) os ATs são descritos como grave problema de saúde pública pelo fato da singular relevância ao que se refere aos impactos sociais e econômicos, ou seja, "não somente pelos custos econômicos provocados, mas, sobretudo, pela dor, sofrimento e perda de qualidade de vida imputados às vítimas, seus familiares e a sociedade como um todo".

Podem ser identificados diversos tipos de perdas nos vários âmbitos econômicos, a julgar pela perda relacionada à produção, onde há a interrupção temporária ou permanente das atividades realizadas pelos envolvidos, além da que faz referência ao desprendimento de custos como conserto ou mesmo reposição de veículos, custos médico-hospitalares, considerando a demanda de recursos humanos e de materiais e especialidades utilizadas para socorro e resgate da vítima, custos com reabilitação, custos judiciais, custos congestionais, custos com previdência social, custos com remoção do veículo e custos do atendimento policial ou dos agentes de trânsito. ${ }^{(12)}$

Além disso, é de suma importante salientar que toda a sociedade e em particular, os sistemas de saúde arcam com custos elevadíssimos das mortes e incapacidades físicas decorrentes desses acidentes, o que impacta diretamente no Produto Interno Bruto (PIB). A OMS estima que no mundo todo as perdas anuais devido aos ATs ultrapassem US\$500 bilhões. No Brasil, o Instituto de Pesquisa Econômica Aplicada (IPEA) estima que os custos totais dos acidentes sejam de $R \$ 28$ a 30 bilhões de reais ao ano. ${ }^{(25)}$

Ao mesmo tempo, se destaca o impacto financeiro provocado pelo AT na estrutura familiar da vítima, entre eles os gastos inesperados para tratamento, reabilitação e reestruturação da família (principalmente quando o AT envolve o responsável pela manutenção financeira do lar) do vitimado. Nesta linha, além dos impactos financeiros tem-se os impactos emocionais, visto que 0 processo de hospitalização envolve o medo da perda, dentre outras questões. (24) "Em todo mundo, os acidentes de trânsito são responsáveis por $12 \%$ do total de mortes, sendo a terceira causa mais frequente na faixa etária de 1 a 40 anos de idade, 
segundo relatório da Organização Mundial da Saúde (OMS). O documento da OMS também reconhece a complexidade dos ATT e a necessidade de ampliar as ações dirigidas à vigilância, prevenção e controle - visando a Promoção da Saúde." (25)

Diante do exposto, é indispensável citar que, são gastos anualmente no mundo, um valor de aproximadamente $R \$$ 518 bilhões de reais. Sendo que, em Relatório do Estado Global sobre a Segurança nas Estradas, publicado em 2009, foi detectado pela OMS no período de 2004, que, apenas no Brasil, foram registrados um percentual de $2,75 \%$ de mortes em AT, o que correspondeu a 35 mil em 1,27 milhões, das mortes registradas no período. (26)

Deste modo, a gravidade do fato, tem levado as comunidades internacionais a desempenharem esforços para a redução de ATs e embora se tenha tido grandes esforços para formulação de mecanismos de enfrentamento, estes têm se revelado insuficientes, visto que os números de acidentes continuam aumentando, o que deixa clara a necessidade de maiores atividades práticas e de pesquisa nesse sentido. (3)

Ao observar a saúde pública, em termos gerais, percebe-se que esta dedicase ao planejamento, ações e empenhos em prol da proteção e melhoramento da qualidade de vida, de maneira que reduza as quantidades de mortes precoces, incapacidades e sequelas evitáveis através de controle e prevenção. Atualmente, vivencia uma série de problemas, gastos financeiros e obstáculos a seres combatidos, o que justifica por sua vez, a necessidade de estudos e pesquisas contínuas, capazes de fornecer embasamento teórico cientifico para medidas e estratégias mais eficientes e focadas em determinado problema, que neste estudo destaca-se o AT. (27)

A partir de então, a problemática dos ATs em consonância com a saúde pública, envolve o cenário crítico das altas taxas de morbimortalidade, que estão arraigadas tanto à impacto individual, social como também econômico. A grande esperança frente a esta questão é a possibilidade de se ter medidas preventivas direcionadas aos ATs. Inclusive, recentemente em termos econômicos, a grande elevação de gastos com a assistência hospitalar, tem mobilizado até mesmo o Banco Mundial, no incentivo de pesquisas no que se refere à Economia em Saúde. (28)

\subsection{Enfermagem como campo promocional em saúde}

Ao abordar o tema relacionado aos problemas de saúde pública, se faz necessário conhecer o Processo SaúdeDoença (PSD), que por sua vez, é o 
principal indicador dos problemas que afeta a qualidade de vida da população. ${ }^{(29)}$ Tal processo, também é visto por Pauli, Artus e Balbinot ${ }^{(30)}$, como a face do próprio problema, pois o processo saúde doença sempre esteve ligado aos principais problemas na saúde em geral e em diferentes épocas.

O PSD passou por algumas metamorfoses no decorrer dos tempos, sempre de acordo com o estilo de vida e o ambiente em que a humanidade se encontrava. Após a revolução industrial, com o desenvolvimento da microbiologia e descobertas dos agentes etiológicos (bactérias, vírus, protozoários) que causavam as doenças, fez com que o PSD adquirisse um novo significado, em que praticamente, deixou de lado o que antes era conceituado pelo espiritual e/ou o ambiente físico e, assim, definiu a saúde como a ausência de doença, onde para uma pessoa ser considerada saudável, bastava eliminar a doença. Expondo, de certa forma, um limite entre saúde e a doença, considerando apenas a própria doença, deixando de lado o indivíduo e o coletivo, ao qual ele faz parte. ${ }^{(31)}$

Com a revolução industrial surgiram novas mudanças, em se tratando de estilo de vida, ambiente, estresse, alimentação. Logo se percebeu que não se dependia somente da microbiologia para se definir uma pessoa saudável em meio ao processo saúde-doença. A partir de então, a doença não poderia ser definida somente pelas dores e os sofrimentos engessados pela fisiopatologia, mas também, pelos sentimentos e expressões do corpo em relação ao ambiente sociocultural. Assim, em 1947 a OMS passou a definir a saúde como: "Um estado de completo bem-estar físico, mental e social, e não apenas a ausência de doença ou enfermidade". (29)

Deste modo, pode-se afirmar que o PSD define-se da relação entre o homem e o ambiente em que se vive, podendo variar nos diferentes tempos históricos devido às mudanças no ambiente socioculturais $\mathrm{e}$ evolução da biomedicina, ou seja, o resultado desta equação entre o ser humano e os demais fatores, tanto biológicos quanto étnicos, financeiros, sociais, psicológicos, até mesmo espirituais, que determinam, assim, a qualidade de vida do indivíduo, grupo ou sociedade. ${ }^{32,28)}$

$\mathrm{Na}$ atualidade, especificamente no Brasil e sob a égide do PSD e da saúde pública, ressalta-se o Sistema único de Saúde (SUS) como indutor de possibilidades para o alcance de uma maior e melhor qualidade de vida e saúde, uma vez que seus princípios doutrinários e filosóficos se embasam na promoção, 
prevenção, controle e manutenção da saúde da população. (33)

Dentro dessa dimensão promocional encontra-se a enfermagem a qual, segundo publicações do COFEN ${ }^{(34)}$, a enfermagem constitui um componente formado por saberes científico e técnicos próprios, que são reproduzidos por diversas práticas (ensino, assistência e/ou pesquisa), sejam elas no contexto social, ético ou político. Esse conjunto de conhecimentos é aplicado por meio de prestação de serviços à pessoa, à família ou à coletividade, tendo como base o contexto de vida dessas pessoas. Nesse sentido, a enfermagem constitui uma profissão que visa à qualidade de vida e saúde, atuando na promoção, prevenção, recuperação e reabilitação do estado de saúde.

Fazendo referência à Lei do exercício profissional desta categoria, ํㅡ 7498 de 25 de junho de 1986, o profissional enfermeiro surge no âmbito da saúde como um integrante da equipe e gestor do serviço de saúde. Cabendo-Ihe, por conseguinte, a execução de algumas atividades de enfermagem que ao considerar a temática deste estudo, aproveita-se para citar como exemplo, a realização de atividades de educação para a população. ${ }^{(8)}$

Com base no mesmo autor, é de valor destacar que entre todas as atividades desenvolvidas pela equipe de enfermagem, algumas são evidenciadas como privativas do profissional enfermeiro, como direção, chefia, organização, planejamento, coordenação, supervisão e avaliação dos serviços prestados.

Ao elencar o planejamento e a supervisão como exemplo, (considerando apenas os itens citados como atividades privativas do profissional enfermeiro), Gama ${ }^{(35)}$ afirma serem indispensáveis para a realização de um trabalho eficiente de uma equipe, por considerar que a qualidade ou até mesmo a ineficiência dessas ferramentas de gestão, refletem diretamente nas características do trabalho da equipe.

Sob a lógica da prevenção e promoção em saúde, o enfermeiro é identificado enquanto profissional importante na composição da equipe de saúde e indispensável para eficiência das ações desenvolvidas, uma vez que possui formação mais generalista e humanística, com foco em promoção, prevenção e ações básicas em saúde. (36)

Referente às atividades desenvolvidas pela Atenção Básica à Saúde (ABS), representada pela Estratégia e Saúde da Família (ESF), a qual é considerada como o primeiro setor de assistência e/ou porta de entrada para os demais serviços de saúde, o enfermeiro trabalha, principalmente, com promoção e 
prevenção dentro de uma área territorial delimitada, destacando seu valor. Ele é o profissional que trabalha mais próximo da equipe de saúde e também da população, o que permite diálogo, interação e conhecimento da situação real, possuindo, simultaneamente, arcabouço teórico, cientifico e prático, condições que permitem a realização de atividades de orientações e educação em saúde com base na demanda de necessidades em saúde, dada a essa interação a qual fornece ferramentas para a construção de um diagnóstico situacional, direcionando assim, as ações a serem desenvolvidas. ${ }^{(37)}$

Ainda neste meio, o trabalho de prevenção e promoção em saúde, estendese desde medidas adotadas em um atendimento individualizado até medidas coletivas. Além disso, as atividades devem considerar e respeitar as particularidades do indivíduo ou da coletividade, tais como crenças, medos, cultura, religião $\mathrm{e}$ bagagem de conhecimento da população, de maneira a ampliar a aceitação do público, e concomitantemente, os resultados positivos, como também, tais atividades devem privilegiar ações que orientem para que a comunidade (coletivo) consiga atuar em favor da própria qualidade de vida. ${ }^{(38)}$

Utilizando afirmativas de Borges ${ }^{(18)} \mathrm{e}$ tomando por base as medidas de prevenção ao AT que visam, basicamente, a mudança positiva de comportamento dos indivíduos frente ao trânsito, reconhece-se ser necessário o conhecimento prévio de condutas e medidas incorretas, adotadas pelos usuários do trânsito, o que torna a presença do profissional enfermeiro indispensável, principalmente, ao que se refere a maneira pela qual é desenvolvido o trabalho do enfermeiro. Assim, a equipe de enfermagem, deve valer-se da variabilidade de ações que a sua profissão the confere, bem como do fato de poder criar estratégias junto à comunidade, auxiliando no enfrentamento do AT, trabalhando, principalmente, os itens que mais causam a ocorrência deste na área determinada.

Porém, de acordo com Almeida (14), "[...] quase nada se faz em termos de prevenção, educação e intervenção com a finalidade de aumentar a consciência e mudar a cultura e os valores sociais da população em relação ao trânsito...". Acrescenta também, que as medidas, Leis e políticas para o trânsito são, em sua grande parte, restritivas aos condutores, como também, as autuações. Sendo que, por exemplo, para manter a aplicabilidade das Leis constantemente, geram custos altíssimos e o Brasil está apresentando uma melhora muito lenta diante do atual cenário. 
O conteúdo exposto corrobora para com a valorização, bem como enfatiza a importância dos atributos do enfermeiro no contexto de prevenção e promoção, sendo indispensável que este profissional se empodere do seu papel e compreenda suas responsabilidades, de maneira a buscar meios e estratégias que colaborem para a eficiência das ações e resultado positivo, ao que se refere à problemática em questão. (39)

Do rol das áreas de atuação do enfermeiro, cita-se exemplos de ações ligadas ao Programa de Saúde na Escola (PSE), direcionadas a adolescentes e préadolescentes, estes tidos como os futuros condutores.

Nessas ações educativopromocionais, o enfermeiro pode expor o AT como um grave problema que ocorre na vida cotidiana, por meio da utilização de vídeos, atividades lúdicas, distribuição de materiais educativos e palestras, de forma a estimular pensamentos críticos, opiniões e discussões ${ }^{(18)}$.

Salienta-se que diante da proximidade que 0 enfermeiro possui com a comunidade, ele pode usufruir da equipe que compõe a ESF, como também valer-se das diferentes campanhas adotadas pelo MS e pelo SNT em prol da vida e/ou do combate ao AT, atuando na implementação de ações educativo-preventivas e de promoção da saúde, com a finalidade de sensibilizar a população. Cabe ainda mencionar que o MS tem desenvolvido diversas ações visando ao combate do AT, entre as quais tem-se a Semana Nacional do Trânsito, que faz referência ao Dia Nacional do Trânsito , 25 de Setembro com alusão à data de sua criação do CTB em 1997. $(18,15)$

\section{CONSIDERAÇÕES FINAIS}

A elaboração desse estudo permitiu ampliar conhecimentos sobre temáticas envolvendo os ATs, uma vez que esta tem sido foco de diversas discussões e já é tida a por muitos pesquisadores como importante problema de saúde pública, não apenas no Brasil, como no mundo.

A incidência de AT tem ampliado bastante nos últimos tempos, o que culminou com o aumento dos índices de morbimortalidade neste contexto (feridos, mutilados e mortos). As principais causas de AT apontadas por este estudo, ao contrário do muitos pensam, não estão relacionadas apenas com as questões de más condições das vias e falta de sinalização, porém, em sua maioria, estão associadas às condutas adotadas pelos integrantes do trânsito, entre elas a embriaguez na direção, o excesso de velocidade e o uso de aparelho celular durante a condução do veículo. 
Dessa maneira, torna-se evidente a necessidade de maiores atitudes e ações no contexto de promoção e prevenção direcionadas a essa problemática, com vistas a sensibilizar a população ao que se refere à mudança de atitudes e adoção de medidas mais seguras.

Infere-se que os gastos com prevenção e promoção de saúde, são claramente inferiores aos gastos correspondentes à ocorrência de um AT, explicitando dessa forma, a reparação de veículo, atendimento médico hospitalar, custos judiciais, tratamento e reabilitação, previdência social e outros, valendo mencionar que o número elevado de AT

\section{REFERÊNCIAS}

1. Abreu, AMM et al. Uso de álcool em vítimas de acidentes de trânsito: estudo do nível de alcoolemia. Rev. Latino-Am. Enf. Brasil, 2010. Disponível em: http://www.scielo.br/pdf/rlae/v18nspe/a05v 18nspe

2. Almeida, ND; Acidentes no trânsito e consumo de álcool: um problema de saúde pública. R. Dir. sanit., São Paulo v.15 n.2, p. 108-125, 2014.

3. Alves, EV. A Agenda Governamental Brasileira e a Década de Ações pelo Trânsito Seguro. 2014. 28 f. Monografia (Especialização). Escola Nacional de Administração Pública (ENAP). Diretoria de Formação Profissional. Brasília, 2014. Disponível em: http://repositorio.enap.gov.br/bitstream/han dle/1/1960/Everaldo\%20_Alves_TCC_EGP 9.pdf? sequence $=1$ \&isAllowed $=\mathrm{y}$ tem causado grande ônus aos cobres públicos brasileiros.

Nessa perspectiva, o profissional enfermeiro destaca-se, sobretudo como promotor de saúde, dada a sua formação humanística, com foco em educação em saúde e para a saúde, além de possuir uma atuação mais próxima da população, favorecendo dessa forma, a elaboração de estratégias mais eficazes e efetivas.

Assim, intenciona-se com este estudo uma singela contribuição, com vistas à elaboração e ao fortalecimento de políticas promocionais, dando maior autonomia aos sujeitos usuários dos serviços e bens de saúde pública.

4. Bastos YGL, Andrade SM, Soares DA. Características dos acidentes de trânsito e das vítimas atendidas em serviço préhospitalar em cidade do Sul do Brasil, 1997/2000. Disponível em: http://www.scielo.br/pdf/\%0D/csp/v21n3/15 .pdf

5. Borges, CPS. Influência do álcool em acidentes de trânsito: o papel do enfermeiro na adoção de medidas preventivas. 2013. 55 f. Monografia (Especialização). Universidade Federal de Minas Gerais. Curso de Especialização em Atenção Básica em Saúde da Família. Araçuai, 2013. Disponível em: https://www.nescon.medicina.ufmg.br/bibli oteca/imagem/4087.pdf

6. BRASIL. Anatomia dos Acidentes. Rev. Inf. Deb. Inst. Pesq. Econ. Aplic. Brasil, $2005 . \quad$ Disponível em: http://www.ipea.gov.br/desafios/index.php? 
option=com_content\&view=article\&id $=164$ $7:$ catid $=28 \&$ ltemid $=23$

7. BRASIL. Departamento de Transito (DETRAN). Educação para o Transito. História do Trânsito Brasileiro. Paraná, 2006a. Disponível em: http://www.educacaotransito.pr.gov.br/mod ules/conteudo/conteudo.php?conteudo $=49$

8. BRASIL. Departamento de Transito (DETRAN). Educação para o Trânsito. Curiosidades. Paraná, 2006b. Disponível em:

http://www.educacaotransito.pr.gov.br/mod ules/conteudo/conteudo.php?conteudo=12 3

9. BRASIL. Departamento Estadual de Trânsito. Diretoria Técnica de Operações (DTO). Coordenadoria do Registro Nacional de Acidentes e Estatísticas de Trânsito(RENAEST). Anuário Estatístico de Acidentes de Trânsito, Rondônia 2014. Rondônia, 2014a. Disponível em: http://www.detran.ro.gov.br/wpcontent/plugins/downloadsmanager/upload/ANUARIORONDONIA2014-2.pdf

10. BRASIL. DETRAN. Resolução № 432 , de 23 de Janeiro de 2013. Brasil, 2013. Disponível em: http://www.denatran.gov.br/download/Reso lucoes/(resolu\%C3\%A7\%C3\%A30\%20432 .2013c).pdf

11. BRASIL. Instituto de Pesquisa e Economia Aplicada (IPEA). Impactos Sociais E Econômicos Dos Acidentes De Trânsito Nas Aglomerações Urbanas. Brasília, 2003. Disponível em: http://www.pedestre.org.br/downloads/lpea SinteseAcidentesTransitoMaio2003.pdf

12. BRASIL. Ministério da Justiça. Secretaria Nacional de Políticas sobre Drogas. Efeitos das Substâncias Psicoativas. Brasília, 2014b. Disponível em: http://www.supera.senad.gov.br/wpcontent/uploads/2016/03/SUP7_Mod2.pdf Abreu, AMM. Mortalidade nos Acidentes de
Transito na Cidade do Rio de Janeiro Relacionada ao Uso e Abuso de Bebidas Alcoólicas. Rio de Janeiro, 2006. $155 \mathrm{f}$. Tese. (Doutorado). Universidade Federal do Rio de Janeiro. Centro de Ciências da Saúde. Escola de Enfermagem Anna Nery. Coordenação Geral de Pós-Graduação e Pesquisa. Curso de Doutorado em Enfermagem. Núcleo de Pesquisa de Enfermagem em Saúde Coletiva. Disponível em: http://bases.bireme.br/cgibin/wxislind.exe/i ah/online/?/sisScript=iah/iah. $x$ is \&src=googl e\&base $=$ LILACS\&lang $=p \&$ nextAction $=$ Ink \& exprSearch $=478399$ \&indexSearch $=$ ID

13. BRASIL. Ministério da Saúde. Entre Mortes e Feridos, Vítimas de Acidentes no Trânsito são Custo para a Sociedade e Problema para o Sistema de Saúde Pública do Brasil. Rev. Discus. Brasil, 2012. Disponível em: http://www.senado.gov.br/noticias/Jornal/e mdiscussao/motos/saude-publica/entremortes-e-feridos-vitimas-de-acidentes-notransito-sao-custo-para-a-sociedade-eproblema-para-o-sistema-de-saudepublica-do-brasil.aspx

14. BRASIL. Ministério da Saúde. Impactos Econômicos dos Acidentes de Trânsito Incentivo a Segurança no Transito. Brasil, 2015.

Disponível em:http://promocaodasaude.saude.gov.br/ promocaodasaude/assuntos/incentivo-aseguranca-no-transito/noticias/impactoseconomicos-dos-acidentes-de-transito

15. BRASIL. Ministério da Saúde. Secretaria de Vigilância em Saúde. Departamento de Análise de Situação em Saúde. Mortalidade por Acidentes de Transporte Terrestre no Brasil. Brasília, 2007b. Disponível em: http://bvsms.saude.gov.br/bvs/publicacoes/ livro_mortalidade_transito.pdf

16. BRASIL. Ministério da Saúde. Secretaria Executiva. Direitos dos Usuários dos Serviços e das Ações de Saúde no Brasil: Legislação, Federal Compilada - 
1973 a 2006. Editora Ministério da Saúde. Brasília, 2007a.

17. BRASIL. Ministério das
Conselho Nacional de

18. BRASIL. Ministério do Planejamento. Orçamento e Gestão. Instituto de Pesquisa Econômica Aplicada (IPEA). Ministério das Cidades e Departamento Nacional de Trânsito (DETRAN). Impactos Sociais e Econômicos dos Acidentes de Trânsito nas Rodovias Brasileiras. Brasil, 2006c. Disponível em: http://www.denatran.gov.br/publicacoes/do wnload/custos_acidentes_transito.pdf

19. BRASIL. Portal Brasil. Cidadania e Justiça. Governo alerta sobre risco do uso de celular no trânsito: Conscientização. Brasil, 2016. Disponível em: http://www.brasil.gov.br/cidadania-ejustica/2016/07/governo-alerta-sobre-riscodo-uso-de-celular-no-transito

20. BRASIL. Presidência da República Casa Civil. Subchefia para Assuntos Jurídicos. LEI № 9.503, DE 23 DE SETEMBRO DE 1997. Institui o Código de Trânsito Brasileiro. Brasil, 1997. Disponível em:

http://www.planalto.gov.br/ccivil_03/leis/L9 503.htm

21. COFEN. Conselho Federal de Enfermagem. Código de Ética dos Profissionais de Enfermagem. Rio de Janeiro, 2007. Disponível em: http://www.coren-sp.gov.br/node/35326

22. Costa GMC, Gualda DMR. Antropologia, Etnografia e Narrativa: Caminhos que se Cruzam na Compreensão do Processo Saúde-Doença. História, Ciências, Saúde. Manguinhos, 2010. Disponível em: http://www.producao.usp.br/bitstream/hand
le/BDPI/3947/art_GUALDA_Antropologia_ etnografia_e_narrativa_caminhos_que_se _2010.pdf? sequence $=1$ \&isAllowed $=y$

23. Filho FMP. O que é Saúde Pública? Cadernos de Saúde Publica. Rio de Janeiro, 1987. Disponível em: http://www.scielo.br/pdf/csp/v3n1/v3n1a07. pdf

24. Franz CM; Seberino JRV. A História do Transito e Sua Evolução. 2012. $24 \mathrm{f}$, Monografia (Especialização). O Portal do Transito Brasileiro. Especialização em Gestão. Educação e Direito de Transito. Joinville, 2012. Disponível em: http://www.transitobr.com.br/downloads/a historia_do_transito_e_sua_evolucao.pdf

25. Gama BMBM. Universidade Federal de Juiz de Fora. Faculdade de Enfermagem. Departamento de Enfermagem Básica. Disciplina de Administração em Enfermagem II. Supervisão Em Enfermagem. Juiz de Fora, 2014. Disponível em: http://www.ufjf.br/admenf/files/2014/08/Sup ervis\%C3\%A3o-emEnfermagem.pdf

26. OMS. ORGANIZACIÓN MUNDIAL DE LA SALUD. Informe mundial sobre prevención de los traumatismos causados por el transito. Resumen. Ginebra, 2004. Disponível em: http://www.who.int/violence_injury_preventi on/publications/road_traffic/world_report/su mmary_es.pdf

27. Paula CG et al. Atuação. do Enfermeiro da Atenção Básica Frente ao Controle do Câncer Uterino: Revisão de Literatura. Rev. Cent. Univ. New. Pai. Brasil, 2012. Disponível em:

http://blog.newtonpaiva.br/pos/wpcontent/uploads/2013/04/PDF-E5-S33.pdf

28. Pauli LST, Artus SC, Balbinot RAA. A Perspectiva do Processo Saúde-Doença na Promoção de Saúde da População. Rev. Dir. Sanit. Brasil, 2003. Disponível em: www.revistas.usp.br/rdisan/article/downloa $\mathrm{d} / 81032 / 84680$ 
29. Rocha JBB; Zeitoune RCG. Universidade Estadual do Rio de Janeiro. Perfil dos Enfermeiros do Programa Saúde da Família: Uma Necessidade para Discutir a Prática Profissional. Rev. Enf. UERJ. Rio de Janeiro, 2007. Disponível em: www.facenf.uerj.br/v15n1/v15n1a07.pdf

30. Santos DS et al. Processo SaúdeDoença e Estratégia de Saúde da Família: o Olhar do Usuário. Rev. Latino-Americ. de Enf. Maceió, 2014. Disponível em: http://www.scielo.br/pdf/rlae/v22n6/pt_0104 -1169-rlae-0002-2496.pdf

31. Silva JLL. O Processo Saúde-Doença e sua Importância para a Promoção da Saúde. Informe-se em Promoção da Saúde. Brasil, 2006. Disponível em: http://www.uff.br/promocaodasaude/o\%20p rocess.pdf

32. Smeltezer SC, Bare BG. Tratado de Enfermagem Médico Cirúrgica. 10 ed. Rio de Janeiro: Guanabara Koogan, 3v. 2006.

33. TeiceiraRA, Míshim SM. Perfil dos Trabalhadores de Enfermagem no Programa de Saúde da Família. Resista Brasileira de Enfermagem. Brasília, 2000. Disponível em: http://www.scielo.br/pdf/reben/v53n3/v53n3 a06.pdf

34. Thielen, IP; Hartmann, RC; Soares, DP. Universidade Federal do Paraná. Núcleo de Psicologia do Trânsito. Percepção de risco e excesso de velocidade. Cad. Saúde
Pública. Curitiba, 2008. Disponível em: http://www.scielo.br/scielo.php?script=sci arttext\&pid=S0102-311X2008000100013

35. Vianna LAC. Curso de Especialização em Saúde da Família-UNA-SUS. Universidade Federal de São Paulo (UNIFESP). Processo saúde-doença. São Paulo, 2012. Disponível em: http://www.unasus.unifesp.br/biblioteca_vir tual/esf/2/unidades_conteudos/unidade $01 /$ unidade01.pdf

36. Waiselfisz JJ. Acidentes de Transito e Motocicletas. Mapa de Violência 2013. Rio de Janeiro, 2013. Disponível em: http://www.mapadaviolencia.org.br/pdf201 3/mapa2013_transito.pdf

37. WHO. WORLD HEALTH ORGANIZATION. Violence and Injury Prevention. Global status report on road safety 2013: supporting a decade of action. WHO Library. Genebra, 2013. Disponível em:http://www.who.int/violence_injury_prev ention/publications/road_traffic/world_repor t/summary_es.pdf

38. Zimmermann, CO. Lado Oculto dos Acidentes de Trânsito. 2008. 59 f. Monografia. (Mestrado). Universidade Católica Dom Bosco. Curso de Psicologia. Campo Grande, 2008. Disponível em: http://newpsi.bvs-

psi.org.br/tcc/CamilaZimmermann.pdf

\section{Como citar (Vancouver)}

Maia RCB, Santos RAS, Souza RAAR, Pereira RA. Acidente de trânsito e enfermagem: uma parceria necessária no contexto da promoção de saúde. Rev Cient Fac Educ e Meio Ambiente [Internet]. 2017;8(2):103-123. DOI: http://dx.doi.org/10.31072/rcf.v8i2.503 